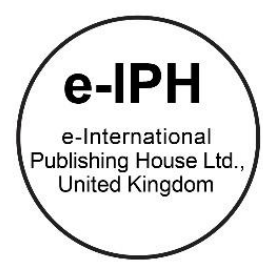

\title{
Identifying Risky Space in Neighbourhood: an Analysis of The Criminogenic Spatio-temporal and Visibility on Layout Design
}

\author{
Fazzami Othman, Zaharah Mohd Yusoff, Siti Aekbal Salleh \\ Faculty of Architecture, Planning and Surveying, \\ Universiti Teknologi MARA (UiTM), Shah Alam, 40450, Malaysia \\ fazzamiothman@gmail.com, zmy1208@uitm.edu.my, aekbal@uitm.edu.my \\ Tel: +60132484687
}

\begin{abstract}
The distribution of crime is not uniform across either time or space and believed influenced by environmental design. This study examines the layout and identifies the risky space in a residential area of Kuala Lumpur. Four space syntax parameters and three years of burglary data analysed across two neighbourhoods. The correlation between the burglary rate and the parameter value carried out to identify the relationship. Results show a significant relationship between visibility parameter and burglary rate while there were similarities temporal patterns for both study areas. Results help planners and authorities to prevent crime through environmental design.
\end{abstract}

Keywords: residential burglary; space syntax; natural surveillance; crime pattern

eISSN: 2398-4287 @ 2019. The Authors. Published for AMER ABRA cE-Bs by e-International Publishing House, Ltd., UK. This is an open access article under the CC BYNC-ND license (http://creativecommons.org/licenses/by-nc-nd/4.0/). Peer-review under responsibility of AMER (Association of Malaysian Environment-Behaviour Researchers), ABRA (Association of Behavioural Researchers on Asians) and cE-Bs (Centre for Environment-Behaviour Studies), Faculty of Architecture, Planning \& Surveying, Universiti Teknologi MARA, Malaysia.

DOI: https://doi.org/10.21834/e-bpj.v4i12.1908

\subsection{Introduction}

Visibility and urban design are relating to each other to create a sustainable and safe city. High demand for the resident to live in a safe place has brought to several initiatives by Malaysia's government to compensate. In advance, a safe city program created to raise public safety by implementing a strategy of crime prevention through environmental design. The idea is to prevent and reduce the fear of crime from the practical design of the physical environment. Besides that, it also increases the quality of the situation, life and reduction of cost. According to Cozens and Love (2015), the efficiency of design by implementing natural strategies can reduce costs and resources compared to the management and mechanical approaches. Through efficient design, safety can reduce naturally, especially for new development. The main principle of crime prevention through environmental design (CPTED) is to increase the awareness of the public. This approach has put an 'eye on the street' as the main principle to reduce the criminal's confidence to commit the crime. Thus, high visibility to create a bright and ample opportunity for surveillance from a various angle is the main idea either indoor nor outdoor.

People naturally watch as long as they use that street, thus an increase in the surveillance and cut fearfully among the community help to reduce crime. Road with intense levels of prospect-refuge (most excellent visibility, few hiding places and higher accessibility) is less dangerous and more preferred than a street with a lower level of prospect-refuge. Summers and Johnson (2017) identically explained the importance used of layout design for crime prevention. According to the study, layout with the good permeability and exceptional design of the street segment recorded the smallest number of outdoor crimes. As analysed using space syntax, the arrangement in Borough, London, which recorded ( $\mathrm{N}=477$ offences) typically happened at the lower surveillance and segments with the highest global choice values. Natural surveillance becomes a crucial element of crime prevention. It also repeatedly mentions in the CPTED implementation guideline to offer higher visibility. However, there is a problem with how to identify the high visibility space and

eISSN: 2398-4287 @ 2019. The Authors. Published for AMER ABRA cE-Bs by e-International Publishing House, Ltd., UK. This is an open access article under the CC BYNC-ND license (http://creativecommons.org/licenses/by-nc-nd/4.0). Peer-review under responsibility of AMER (Association of Malaysian Environment-Behaviour Researchers), ABRA (Association of Behavioural Researchers on Asians) and cE-Bs (Centre for Environment-Behaviour Studies), Faculty of Architecture, Planning \& Surveying, Universiti Teknologi MARA, Malaysia. DOI: https://doi.org/10.21834/e-bpj.v4i12.1908 
how it could increase the safety level. This study began with the assumption that urban layout design affects the crime distribution by a different visibility degree based on the existing development components. Therefore, it was necessary to investigate the potential part and composition that affect the visibility degree and how the crime pattern was.

\subsection{Purpose of the study}

The purpose of this study was to examine the layout design between two adjacent neighbourhoods based on the existing development component and identify the visibility degree on every space of the street segment. The result compared to the distribution of burglary (selection of crime type based on the high crime rate and highly related to the property developer). Finally, it expected to suggest the characteristics of a layout design that can reduce the burglary rate.

\subsection{Objective of the study}

The objective of the study was to identify the temporal pattern of burglary, to evaluate the visibility parameters for both residential layouts based on the characteristic of the street segment, and to determine the statistical relationship between the visibility parameters and burglary distribution.

\subsection{Literature Review}

The use of space remains a critical issue to maximising visibility for a city street and neighbourhood area. Promoting natural surveillance for maximising visibility is recommended by a good deal of crime prevention theories and studies. Defensible space and space syntax is the main theories to deliver a solution to crime reduction. Defensible space represents the theory that is focusing on territoriality and natural surveillance. This theory wants to relate to crime and space when both reliable retains a connection. Otherwise, it also promotes the ability of the residents to monitor their surrounding area. Simultaneously, the space syntax theory focuses on configuration accessibility. According to Summers and Johnson (2017), any potential movement, people, and use of space are one of the configuration characteristics related to the crime occurrence. The reason is that any enclosed space could remain a potential place for offenders to commit a crime and called it an opportunity. Many studies discussed these elements could promote the encountering and maximising the usable space if they were visually enough. Patterson (2016) determines the barriers and access in the layout should be controlled and maintain properly to avoid any disrupting phenomenon related to the crime. The best way is to produce a visible space by requiring natural surveillance as a critical factor. A study by Lee and $\mathrm{Ha}(2015)$, which observe several CPTED measures and walking frequencies in 12 neighbourhoods in Seoul, Korea revealed that sufficient closed-circuit television and maintenance performed a significant role in mitigating fear of crime. They use structural equation modelling, and it shows that people are avoiding using the street under supervision as reflected to remain a potential victim. In a term of surveillance and layout, identifying the possible crime is recommended studying on the street configuration at the micro-level. In general, at least with layout design, the evidence suggests that more porous layout can reduce the crime rate (Kigawa and Seo, 2017; Summers and Johnson, 2017; Bolton et al., 2017; Byun, 2016; Varoudis and Penn, 2015; Ward et al., 2014; Othman, 2014; and Nes and Rueb, 2013).

Identifying risky space in a residential area is not about the design only, but also the other affected element that can contribute to the visibility degree. Crime events are more likely to occur when there is a suitable target and predicted the temporal activity of people. Here, the people's routine is positively related to the opportunity. The study of routine activity could identify how the pattern of crime in a particular area by tracking the availability of the street user; therefore, it determines how space utilized. It also explains how the activity nodes, travel paths and social network of people influence the spatiotemporal of crimes. According to Tang et al. (2017), the travel pattern and activity space of the individual are affecting the crime concentration. The research shows that the highest number of crimes recorded during a weekday than the weekend as more time spent at home, thus minimising the opportunity. The location may be a more significant risk if space is not used and under surveillance. Identifying the crime pattern can assist the police in managing the criminal activity while determining the elements that affected the visibility help the designer in providing sustainable development of the city.

\subsection{Methodology}

\subsection{Study Area}

The study conducted located at the district in Kuala Lumpur, Petaling (Fig. 1). It is a part of a larger populated area and surrounded by strategic land uses, which served a competitive economic structure. This study focused on two residential layouts which adjacently located. The selection of design is made carefully by analysing the burglary level, social homogeneous and street type. However, due to the confidentiality restriction of crime data, the name of the neighbourhood was concealed. 


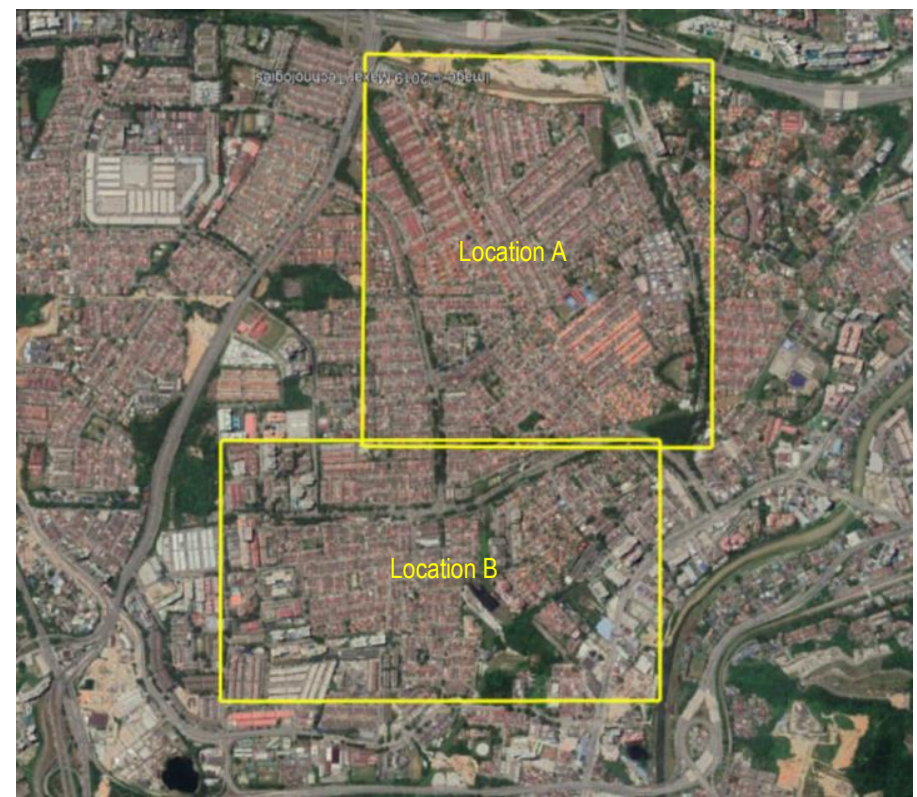

Fig. 1 The overview of study areas gathered from the satellite imagery and labelled as (Location A and B).

\subsection{Data collection}

This study comprises two primary datasets, which include burglary and street user data set. The burglary dataset was obtained from the Royal Malaysian Police (RMP) Department while tracking street user is going through the on-ground survey (Al-Sayed et al., 2014).

\subsubsection{Burglary data set}

The data set used in this study has been reported burglaries in Kuala Lumpur for three years (2014 - 2016) and obtained from the Royal Malaysian Police (RMP) department. The focus of the study is residential burglary; therefore, the data need to go through the filtering process by removing all related to non-residential.

\subsubsection{Street user density}

The dataset obtained from the on-ground survey and using the gate-count method (Al-Sayed et al., 2014). The purpose is to get the frequency of street users in each layout. This study chooses several locations that cover the study area and specifically cover a range of high, moderate, and fewer crime rates per junction. Then, a reasonable 'gate' position is chosen, around ten gates per layout. The observation is taken within 2 hours per three sessions on risk and safe hour. People and vehicles crossing an observer line are counted and recorded precisely.

\subsection{Data Analysis Procedure}

This study consists of Spatiotemporal and visibility analysis. The selection of methods based on previous reviews (Summers and Johnson., 2017; Tang et al., 2017; Varoudis and Penn, 2015).

\subsubsection{Spatiotemporal analysis}

The spatiotemporal analysis is to choose and conducted to identify the crime pattern. The pattern used to explain the social activity and help to suggest the best place for police to more visible among the crime incidents. This analysis consists of spatial location identification and how the pattern of crime based on the date of the event happens. Besides, it will visually and statistically be analysing. The density of burglary incidents is visually examine using Kernel's Density Estimation (KDE), while statistical analysis of crime incidents is using CrimeStat, a spatial statistic program method. Tang et al. (2015) suggested that the integration of both ways was significant to explain the burglary pattern and potentially forecast the future incident.

\subsubsection{Visibility and space analysis}

Analysis of visibility and space used to examine the opportunity in physical layout. Summers and Johnson (2017) believed that this analysis was useful to understand the use of space concerning accessibility and determine how is the characteristic of street configuration. Isovist and space syntax was the best tools to measure the street configuration and the degree of visibility, which believed to affect the burglary distribution as suggest by Varoudis and Penn (2015). Using the statistical test of regression, it can identify the relationship between the burglary rate the degree of visibility. Street user, which represents the regular pattern of the resident, is analysing and compare after. 


\subsection{Interpretation}

The analysis is to interpret the significant relationship between a burglary incident and space configuration. It also illustrates how the layout affects the visibility and regular pattern of the resident. Thus, it would become an essential discussion for a safety and layout design in the future.

\subsection{Findings}

\subsection{Temporal Patterns of Burglary in Neighbourhood Area}

Burglary in both locations A and B shows a similar pattern, as revealed in Fig.2. Site A recorded peak in the early morning (6 am to 9 am) and late afternoon ( $6 \mathrm{pm}$ to $8 \mathrm{pm}$ ). However, during the midnight hours, burglary incidence is low. Location B exhibits a similar pattern but has a different during the afternoon where the incident is high (six cases). The study of crime-temporal must include the pattern design of days. Most of the event is happening during the weekend for location A and B while it is a risk during Monday, Wednesday, and Friday (Fig. 3). As a result, the overall pattern of burglary in both locations is looking similar and predictable.

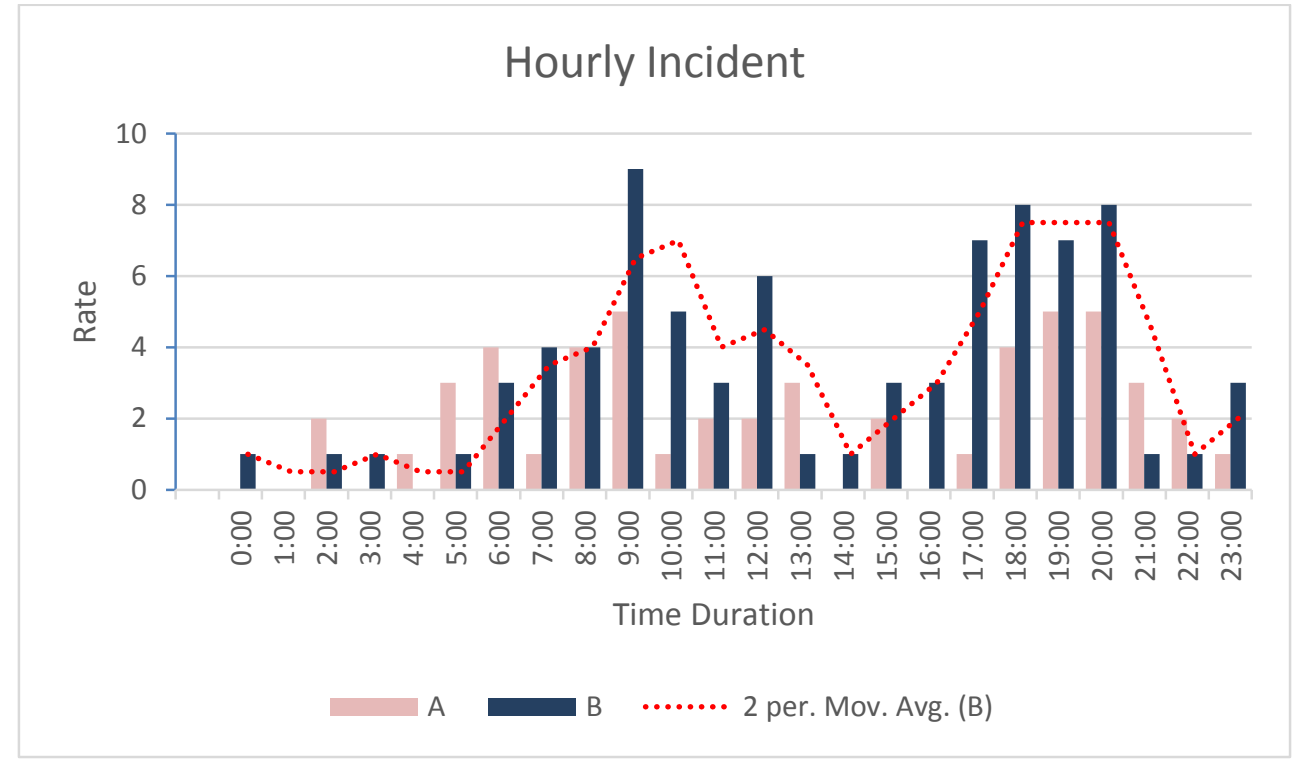

Fig. 2 Hourly incidents of burglary for location A and B

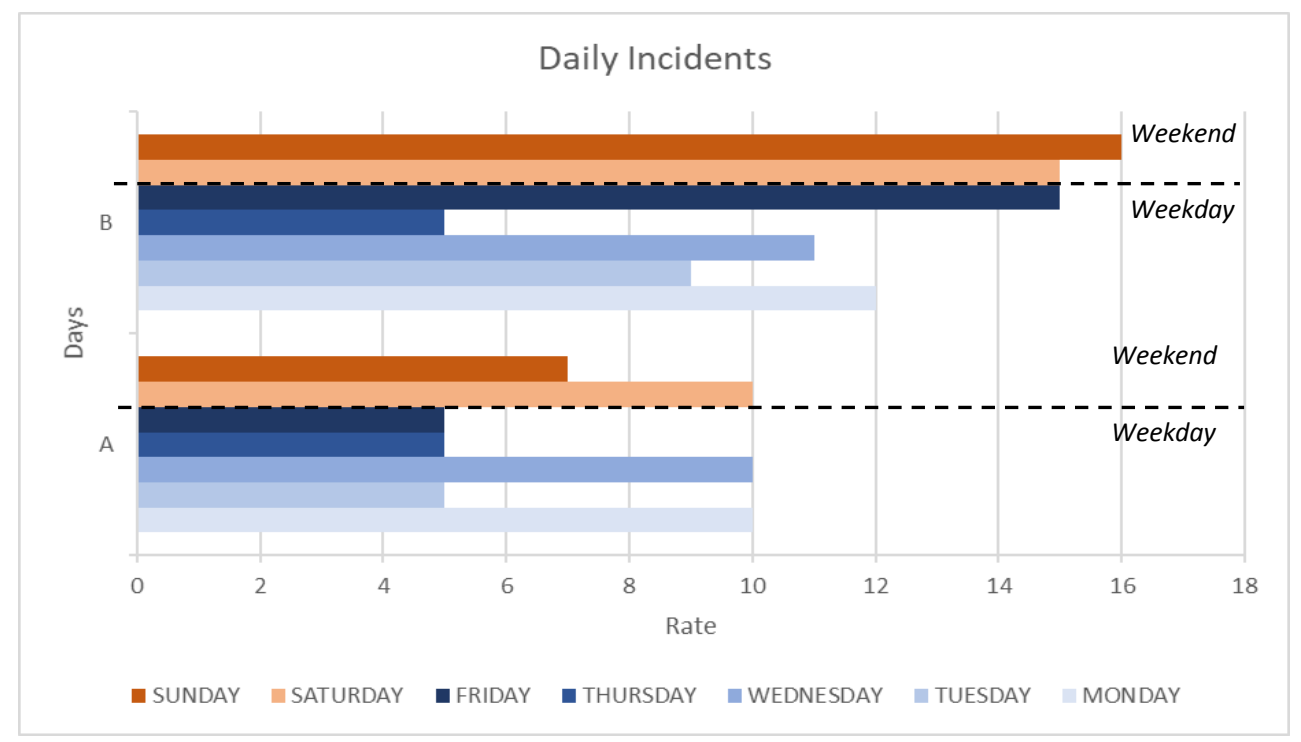

Fig. 3 The daily incident of burglary for location $A$ and $B$

\subsection{Spatial Distribution and Density of Burglary}

Burglary incident in study areas has shown the predictable result of the temporal. This study proceeds with spatial distribution and density to know the risker place of getting offences. By using kernel density estimation and statistical programming of crime, the result shown as Fig 4. Location A shows five high concentration areas (Fig.3 (a)). However, location B only higher concentrated on the left 
(Fig.3 (b)). This density map is useful for police or crime study to focus on reducing and prevent crime. Next, Fig. 3 (c) and (d) show the crime, travel pattern designed based on the date and time of the incident. The mean centre is the intersection of the mean coordinates, while the standard deviational ellipse is counting the skewed distribution, minimising the amount of extra space. Based on both statistical calculations, it helps to place the best position of car patrol to visible and control the area from the crime incidents. To understand the spatial pattern, it analyses the joining line of the event. Location A shows a cluster pattern where the activities concentrate on a single area, but randomly distributed throughout the region. Meanwhile, location B shows the hybrid pattern where it is multiple clusters with a predictable journey.

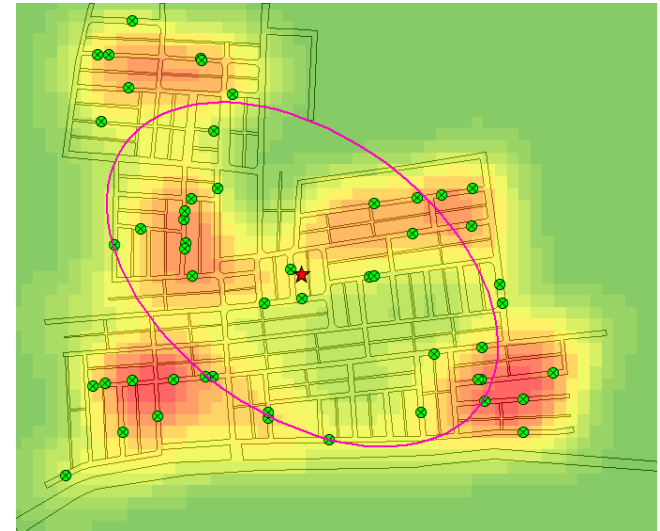

(a)

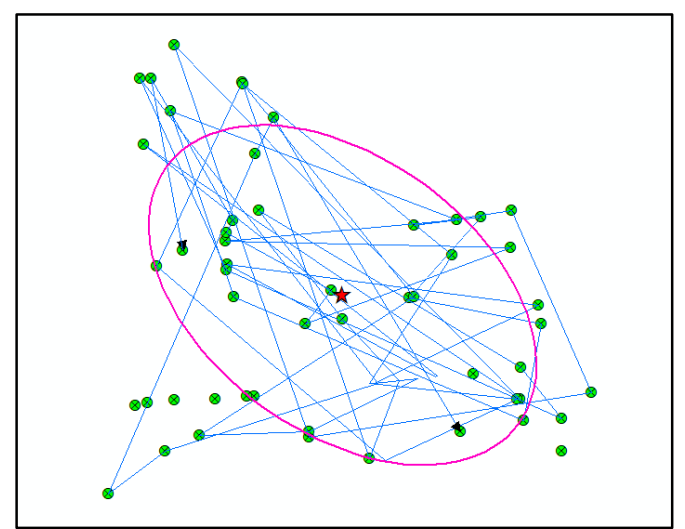

(c)

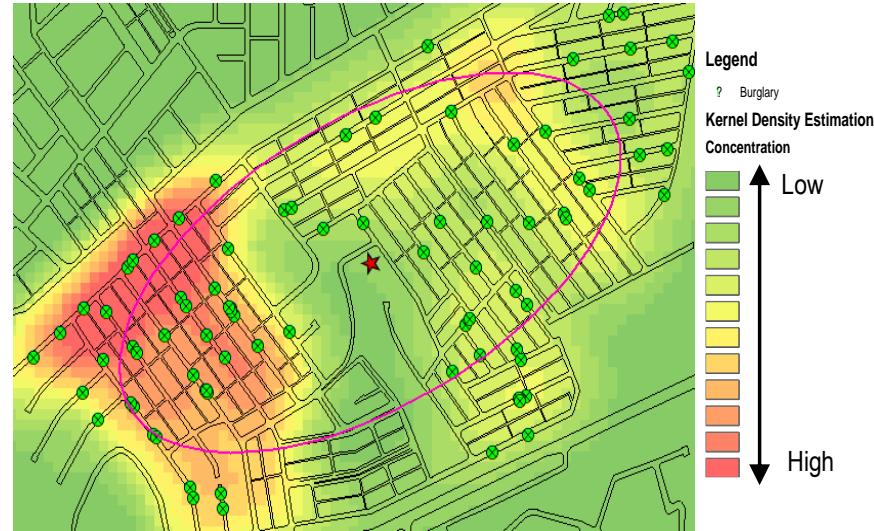

(b)

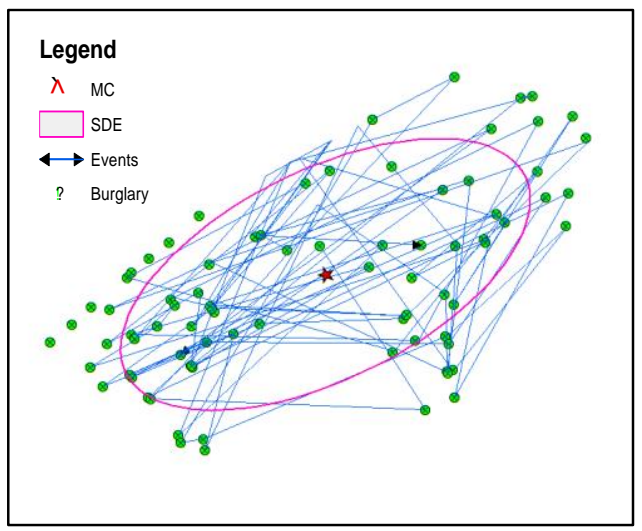

(d)

Fig. 4. (a) The concentration of burglary density for location $A$; (b) The concentration of burglary density for location $B$; (c) Temporal moving of Location A; (d) Temporal moving of location B

\subsection{Degrees of Visibility and Space Used}

This study analyses the layout for a location to get the value of mean depth, integration, connectivity and direct visibility (Fig. 5 and Fig. 6). Focusing on the parameters, it can identify how street space used and how it brings the layout to be surveillance. In this study, it tests the parameters on every street segment of the layout. The study carries out ten samplings of the street segment out to identify the relationship towards the burglary rate. Based on the overall observation, it shows that there is a significant relationship between the parameter of mean depth and burglary rate. Mean depth indicates how deep or centralise of the layout. From layout $A$, it shows that the street number of 5 is the highest depth $(M D=4.06)$ and recorded three numbers of burglary incidents. Mean depth also results the good significant relationship $(P=0.02 ;<0.05)$ from the overall street sampling. As follows, layout $B$ recorded $(P=0.03 ;<0.05)$ but higher than layout $A$. Both are related to the burglary rate. 


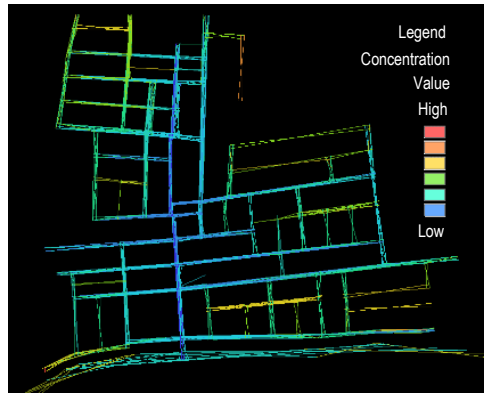

(a)

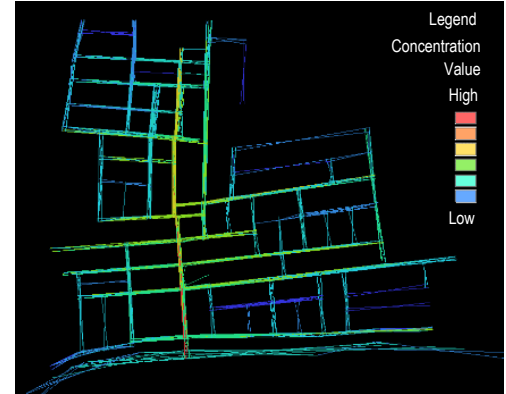

(b)

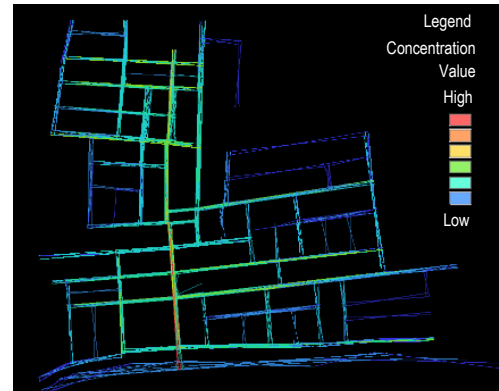

(c)

Fig. 5. (a) The concentration of mean depth; (b) The concentration of integration; (c) The concentration of connectivity

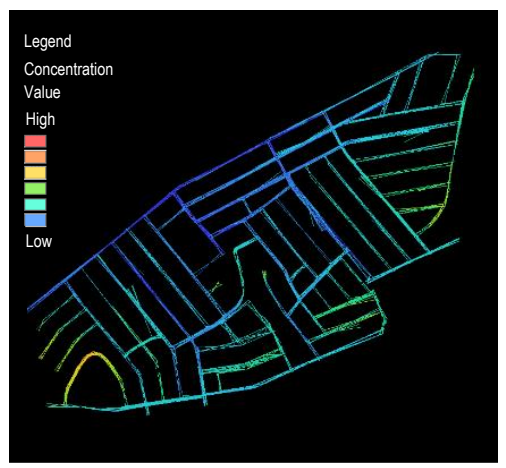

(a)

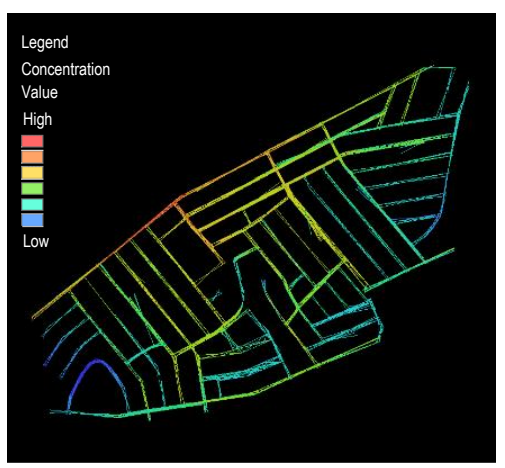

(b)

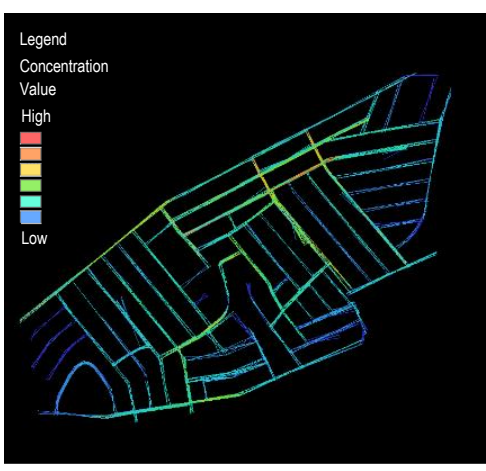

(c)

Fig. 6. (a) The concentration of mean depth; (b) The concentration of integration; (c) The concentration of connectivity

Table 1. The value of each parameter for the street sampling of location $A$ and relationship towards burglary rate.

\begin{tabular}{|c|c|c|c|c|c|c|c|c|c|c|c|c|c|}
\hline \multirow{2}{*}{ Parameter } & \multicolumn{10}{|c|}{ Street (A) } & \multirow{2}{*}{$\begin{array}{l}\text { R- } \\
\text { square }\end{array}$} & \multirow{2}{*}{$\begin{array}{c}\mathrm{P}- \\
\text { value }\end{array}$} & \multirow{2}{*}{ Sig. F } \\
\hline & 1 & 2 & 3 & 4 & 5 & 6 & 7 & 8 & 9 & 10 & & & \\
\hline Mean Depth & 2.69 & 2.37 & 3.31 & 2.37 & 4.08 & 2.68 & 2.40 & 3.38 & 3.44 & 3.40 & 0.49 & $0 . .02$ & 0.02 \\
\hline Integration & 1.94 & 2.40 & 1.42 & 2.40 & 1.07 & 2.08 & 2.33 & 1.37 & 1.34 & 1.36 & 0.6 & 0.009 & 0.009 \\
\hline Connectivity & 8 & 9 & 2 & 9 & 2 & 6 & 9 & 5 & 2 & 3 & 0.717 & 0.002 & 0.002 \\
\hline $\begin{array}{l}\text { Direct } \\
\text { Visibility }\end{array}$ & 8.47 & 5.22 & 3.02 & 6.22 & 3.44 & 3.56 & 9.75 & 5.44 & 2.73 & 2.57 & 0.41 & 0.04 & 0.04 \\
\hline Burglary & 2 & 0 & 5 & 1 & 3 & 2 & 1 & 2 & 3 & 5 & & & \\
\hline
\end{tabular}

Table 2. The value of each parameter for the street sampling of location B and relationship towards burglary rate.

\begin{tabular}{|c|c|c|c|c|c|c|c|c|c|c|c|c|c|}
\hline \multirow{2}{*}{ Parameter } & \multicolumn{10}{|c|}{ Street (B) } & \multirow{2}{*}{$\begin{array}{l}\mathrm{R} \text { - } \\
\text { square }\end{array}$} & \multirow{2}{*}{ P-value } & \multirow{2}{*}{ Sig. $F$} \\
\hline & 1 & 2 & 3 & 4 & 5 & 6 & 7 & 8 & 9 & 10 & & & \\
\hline Mean Depth & 3.58 & 3.66 & 3.23 & 4.17 & 4.85 & 4.10 & 4.08 & 3.60 & 4.27 & 4.20 & 0.5 & 0.03 & 0.03 \\
\hline Integration & 1.53 & 1.48 & 1.77 & 1.24 & 1.03 & 1.17 & 1.28 & 1.52 & 1.21 & 1.23 & 0.58 & 0.01 & 0.01 \\
\hline Connectivity & 6 & 5 & 7 & 2 & 2 & 2 & 3 & 6 & 4 & 4 & 0.84 & 0.0002 & 0.0002 \\
\hline $\begin{array}{c}\text { Direct } \\
\text { Visibility }\end{array}$ & 7.44 & 5.35 & 9.56 & 3.58 & 2.96 & 2.11 & 6.22 & 8.54 & 4.13 & 5.88 & 0.71 & 0.002 & 0.002 \\
\hline Burglary & 1 & 2 & 1 & 5 & 5 & 7 & 4 & 1 & 2 & 2 & & & \\
\hline
\end{tabular}

Integration and connectivity are related to each other, where the higher value of integration indicates the highest value of connectivity. Integration measures the mean shortest path length for all nodes in the layout. Based on the findings (Table 1 and 2 ), Location $A$ and $B$ is strongly related to the burglary rate with both recorded the significant value $(P=0.009 ;<0.05)$ and $(P=0.009 ;<0.05)$. The average value for the entire sampling of location $A$ (1.77) higher than a B (1.36). Finally, it is direct visibility, which expresses how often of any given subject seen from a defined sample region. In this study, it is correlating the area and connectivity when space viewed exactly matches the sample region. Location A recorded higher visibility on street number 7 (9.75), followed by S1 (8.47), S4 (6.22), and S8 (5.88). Street 10 recorded the lowest value is 2.57 and the highest burglary rate of samplings in 5 . Location $B$ is highly visible than location A. The highest value of visibility is recorded on S3 (9.56), followed by S8 (8.54), S1 (7.44), and S7 (6.22). Direct visibility 
significantly relates to the burglary rate for both layouts. However, location $B$ is more significant with $(P=0.002)$ while location $A(P=$ 0.04).

\subsection{Routine Activity in Different Range of Burglary Rate}

An analysis of routine activity conducted by identifies the volume of street users at selected junctions, as shown in (Fig. 7). In this study, the user is counted and compared to integrating the layout since it is related to influence the burglary rate. Besides that, integration also affects the possibility of a street user in a specific area. Based on the result, integrating layout is 68 per cent influenced the movement of street users on selected sampling locations for both arrangements.

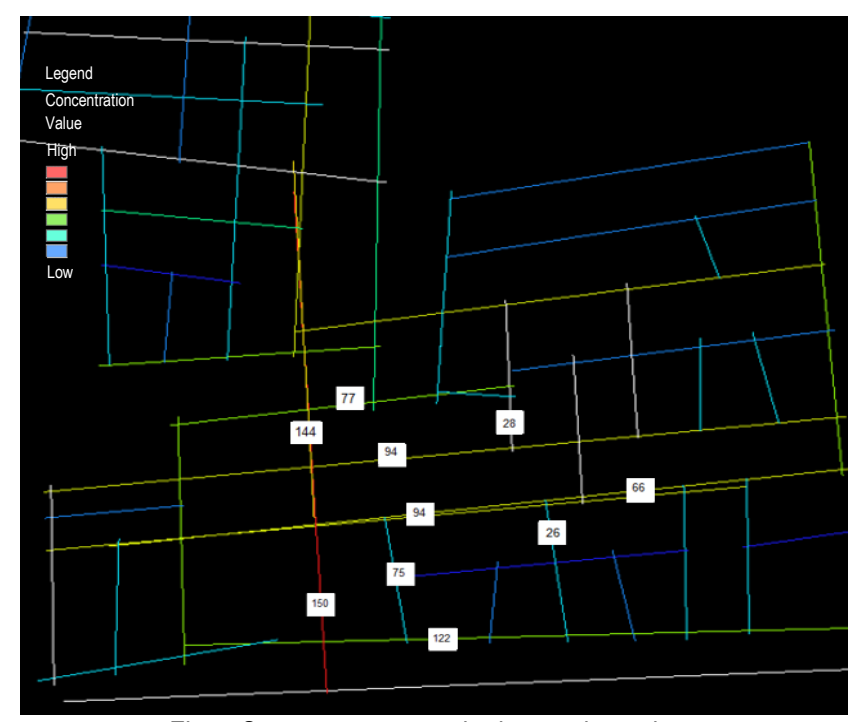

Fig. 7 Street user versus the integration values

\subsection{Discussion}

\subsection{Temporal and Travel pattern of Crime Event}

The temporal model of burglary for both case study areas shows similarity. Here, the study fully discovers the temporal pattern based on the time and date of incidents. Based on hourly events, both locations recorded peak during early morning and stay risk in the late afternoon. Meanwhile, the low burglary rate recorded at midnight. This result supported the data released by the Australian Capital Territory, where the pattern of crime was a typical peak in the early afternoon to mid-afternoon hours (Felson \& Boba, 2010). Based on the daily incident, burglary is riskier to happen on the weekend than weekdays because of the surrounding land use where both locations are near to the shopping complex. This factor could affect the absence of people at home. However, selected weekdays still recorded high burglary incidents, especially on Monday and Friday.

\subsection{Spatial Burglary Pattern and Surveillance}

The study area has shown there is some similarity of pattern based on the temporal and spatial location. Statistical programming of crime developed by the National Institute of Justice has successfully to reduce crime and predictions in Washington, DC (Levine, 2017). This program is useful to identify the best location for police to allocate the patrol in riskier place from being a victim. In this study, standard deviation ellipse and mean centre calculation practised determining the position of patrol so that it is surveillance. The mean centre calculation is probably the best position for a police patrol to respond quickly to incidents and reach all potential targets. It is the simplest of statistics and has been years, calculated to plot the incident in Cartesian planes. Besides that, saturation patrol would best be concentrated in the single standard deviation ellipse, because it encloses a majority of the events and conforms best to the street geography in the study area. The distribution of many known points brings to the density of incidents. Using a single point of events bring a difficult to identify the high concentration of dangerous place. Thus, kernel density estimation is the best way to solve the problem. The frequency of incidents naturally calculated using the nearest neighbour method of every single point. It helps the police and designer to improve the safety level on spotted with high concentration.

\subsection{Significant Relationship between Burglary Rate and Visibility of Street Configuration}

Space syntax and isovist used to identify visibility and risky space. Most of the settings are significantly related to the burglary rate. Mean depth indicates the difficulty of the street user to reach the destination, and it allows the opportunity of the burglary to increase in some manner. Based on findings, the more depth of one location from the centre of the layout promotes a high burglary rate. Besides that, the integration parameter used either globally or locally based on the size of the space. Integration indicates the shortest path length of all nodes. Logically, the higher degree of integration illustrates the high connectivity of the layout, thus bring the potential of the street user. The finding shows that $68 \%$ of the selected street is dense with street users, and this result is in line with the integration 
values. On the other hand, direct visibility is the variable used to test the clarity of space from every node given. In this study, several nodes indicate the edge of every turn made of space in single lines. The straight forward road increases the direct visibility degree of space. All the parameter test has shown a significant relationship against the burglary rate on the selected street with P-value $<0.05$. As a result, high degree values of connectivity, integration and direct visibility promote less crime rate for both study areas.

\subsection{Limitation of Study}

There are several limitations associated with the study. First, the layout was a test based on 2D Cartesian drawing with no value of environmental height, which can affect the value of each parameter. However, the visibility parameter still suitable for the analyzing of space. Second, the movement pattern, which believed could affect the potential crime rate, is measured on the selected time only. Third, the study analyses only on the chosen junction, which depends on the different crime rates in that area. Finally, the location name concealed from the public due to the confidential restrictions of crime data.

\subsection{Conclusion and Recommendations}

There is a significant relationship between the topological parameter of space and the burglary rate in the case study area. Mean depth, integration, connectivity and direct visibility show a great statistical value against the burglary rate in several junctions. Based on the result, a higher amount of integration, connectivity and visibility promote safe space while lower mean depth value provides a riskier place to live. In terms of temporal pattern, there is an issue to forecast the potential incidents for both areas. Location A indicates the movement of the burglary incident is in a cluster pattern where it concentrated in a single domain but randomly distributed. Location $B$ more to the hybrid pattern and predictable, but still not enough. However, the findings have determined the best position for police to allocate the patrol to overcome this problem using the statistical calculation of the mean centre and standard deviation. Based on the result, it concluded that the visibility of space, crime travel, the higher concentration of incidents, and police surveillance were essential to reduce the crime rate. The findings also support the theory of 'eye on the street' where a higher number of street users promote high natural surveillance, which naturally acts as monitoring from any criminal incidents. Highest degree value of integration, connectivity, and mean depth increase the amount of direct visibility, thus reduce the opportunity for criminals. Besides, the findings also help the designer to identify the place that can reduce visibility by controlling the street space. As conclusion, layout with good permeable design gives a tendency to smallest number of burglary, and this support the evidence suggest by several studies that linking the permeability and layout design (Kigawa and Seo, 2017; Summers and Johnson, 2017; Bolton et al., 2017; Byun, 2016; Varoudis and Penn, 2015; Ward et al., 2014; Othman, 2014; and Nes and Rueb, 2013). By emphasizing the space used in the future, it is fulfilling the strategy of the safe city program as environmental design initiatives and preventing crime through environmental design. Further research engaged the micro visibility parameter by including the local attribute and environmental height to get a more precise visibility degree.

\section{Acknowledgement}

This research was funded by the Universiti Teknologi MARA (UiTM) under the FRGS grant with file no: 600-IRMI/FRGS/3(205/2019). Special thanks to the Royal Police Malaysia and individuals who involved in this research.

\section{References}

Al-Sayed, K., Turner, A., Lida, B., \& Penn, A. (2014). Space Syntax Methodology. London, UK: Barlett School of Architecture, UCL.

Bolton, T., Francis, N., \& Froy, F. (2017). The Impact of Space Syntax on Urban Policy Making: Linking research into UK Policy. 11th International Space Syntax Symposium. Lisbon.

Byun, G. (2016). Factors of a Surveillance Environment that Affect Burglaries in Commercial Districts. Journal of Asian Architecture and Building Engineering, vol.15 no.1.

Cozens, P., \& Love, T. (2015). A Review and Current Status of Crime Prevention through Environmental Design (CPTED). Journal of Planning Literature, 30(4).

Felson, M., \& Boba, R. (2010). Crime and Everyday Life. United Kingdom: SAGE Publication, Inc UK.

Kigawa, T., \& Seo, K. W. (2017). FINDING AN IDEAL MODEL FOR COMPACT CITIES WITH MULTIPOLE NETWORKS. 11th International Space Syntax Symposium, (p. 72.1). Lisbon.

Lee, S., \& Ha, M. (2015). The Duality of Visibility: Does Visibility Increase or Decrease the Fear of Crime in Schools' Exterior Environments? Journal of Asian Architecture and Building Engineering, 14 (1), pp.145-152.

Levine, N. (2017). Encyclopedia of GIS. In S. Shekhar, H. Xiong, \& X. Zhou, Encyclopedia of GIS. USA: Springer, Cham.

Nes, A. V., \& Rueb, L. (2013). Spatial Behaviour in Dutch Dwelling Areas- How Housing Layouts Affects the Behaviour of its Users. 7th International Space Syntax Symposium. Stockholm.

Othman, F. (2014). GIS-based Measures of Burglary and Connectivity to Housing Layout. International Real Estate Research Symposium, 7th IRERS. Selangor: INSPEN, Valuation and Property Services Department, Ministry of Finance, Malaysia. 
Patterson, J. L. (2016). Traffic modelling in cities - Validation of space syntax at an urban scale. Indoor and Built Environment, Vol. 25(7) $1163-1178$.

Summers, L., \& Johnson, S. D. (2017). Does the Configuration of the Street Network Influence Where Outdoor Serious Violence Takes Place? Using Space Syntax to Test Crime Pattern Theory. J Quant Criminol, 397-420.

Tang, Y., Zhu, X., Guo, W., Ye, X., Hu, T., Fan, Y., \& Zhang, F. (2017). Non-Homogeneous Diffusion of Residential Crime International Journal of Sustainability, 934.

Varoudis, T., \& Penn, A. (2015). Visibility, accessibility and beyond: Next-generation visibility graph analysis. Proceedings of the 10th International Space Syntax Symposium, (p. 152). London.

Ward, J. T., Nobles, M. R., Youstin, T. J., \& Cook, C. L. (2014). Placing the neighbourhood accessibility-burglary link in the social-cultural context. Crime Dealing, 60 739-763. 